\title{
Editorial
}

\section{Objeción de Conciencia}

En relación a la reciente aprobación en el Senado a la despenalización del aborto por 3 causales a saber riesgo de la vida de la madre, inviabilidad fetal y en caso de violación el Directorio de la Sociedad Chilena de Obstetricia y Ginecología desea manifestar lo siguiente:

1.- Como médicos nuestra primera obligación es velar por nuestros pacientes en todos los aspectos de su salud y por ello sabremos adecuarnos al nuevo marco legal que regirá en el país y actuaremos con responsabilidad respetando el marco jurídico existente.

2.- Nos vemos ante una situación medico social nueva, de carácter complejo que afecta a nuestra sociedad toda y que debemos enfrentar con altura de miras y profundas convicciones.

3.- El proyecto aprobado no obliga a ninguna mujer a abortar, cualquiera sea la causal que a ella la afecte, sino que le entrega la oportunidad para decidir en conciencia y con toda la información disponible para elegir su mejor opción.

4. Es responsabilidad del Estado y sus autoridades el proveer toda la infraestructura de recursos humanos y técnicos para enfrentar en forma adecuada este nuevo desafió que el país le entrega a la salud de la mujer.

5.- Se debe respetar firmemente a aquellos profesionales que por convicción y haciendo uso de sus facultades invoquen objeción de conciencia, sin descuidar que la salud de la mujer se vea comprometida por dichos actos.

6.- Esta Sociedad Científica se encuentra disponible para asesorar técnicamente en los diferentes aspecto que esta Ley involucra, favoreciendo el uso de la mejor evidencia disponible y evitando al máximo la discriminación a los pacientes y a los profesionales de la salud.

\section{Directorio SOCHOG}

En relación al punto 5 de esta declaración OBJECION DE CONCIENCIA me parece relevante ahondar en algunos aspectos de fondo. En la Declaración Universal de los DDHH de 1948 se reconoce el derecho de todo individuo a actuar en base a su propia escala de valores pudiéndose oponer a acciones que vayan en contra de los mismos y que atenten contra su autonomía.

Este es el fundamento de la Objeción de Conciencia que se define como la negativa de una persona a realizar ciertos actos que ordena la ley o la autoridad competente, basado en razones de convicción moral. Implicando por ello una reflexión y un fundamento de por que tomar dicha determinación y no un mero acto de adhesión a una causa.

En base a estos hechos se genera la disyuntiva entre el respeto a las normas jurídicas existentes y las convicciones morales personales de los individuos. Objetar en conciencia es una respuesta individual de quien solicita la eximición de una acción determinada sin implicar un cuestionamiento de la validez de la ley.

En el ejercicio de la Objeción de Conciencia, el médico no puede ni debe obstruir la debida atención de una paciente y es su obligación informar de cómo acceder a ella. En nuestro Código de Ética (articulo 24) se señala "El médico a quien se solicitaren prestaciones que vayan en contra de su conciencia o de su convencimiento clínico, procurará que otro colega continúe asistiendo al paciente, salvo que ello produjere graves e inmediatos daños para la salud del enfermo". Nuestro Colegio considera que ya que el aseguramiento al derecho a la prestación médica es responsabilidad del Estado y no del objetor médico, es el Estado el que debe asegurar dicho acceso.

Estas reflexiones nos deben conducir a buscar el equilibrio y las vías de entendimiento para encontrar el justo punto que permita resguardar los valores de la Objeción de Conciencia, así como los derechos de los 
usuarios a acceder a estas prestaciones, sin convertir esta situación en un conflicto que termine por transformar en "letra muerta lo que la ley ordenó".

Dr. Omar Nazzal Nazal

Presidente Sociedad Chilena de Obstetricia y Ginecología 